\title{
प्रमास्वरूपं तद्भेदाश्च
}

\author{
पुरुषोत्तम आचार्य: \\ उपप्राध्यापक:, न्यायविभाग: \\ नेसंवि, जनताविद्यापीठम, दाड:, नेपाल: \\ Email : pyarapuru@gmail.com
}

(सारसझ्क्षेप : प्रस्तुतोडयमालेख: पौरस्त्यदर्शनेषु प्रामुख्यं भजमानस्य न्यायदर्शनस्य वैशेषिकदर्शनस्य च प्रमाविवेचने केन्द्रितो वर्तते। आलेखेडस्मिन् न्यायवैशेषिकदर्शनाभिमताया: प्रमाया: स्वरूपं तद्भेदाशच निरूपिता: । प्रमाया: भेदनिरूपणक्रमे न्यायदृष्टया प्रत्यक्षानुमित्युपमितिशाब्दादिचतुर्विधप्रमाणां वैशेषिकदृष्टया हि प्रत्यक्षानुमितिभेदेन प्रमाद्वयस्य च वस्तुतत्त्वान्वेषणे प्रयासो विहितोड त्रालेखे । प्रत्यक्षादिप्रमाया यथार्थस्वरूपं विविच्य तद्वति (रजतत्ववति रजते) तत्प्रकारकानुभव: (रजतत्वप्रकारकानुभव:) एव प्रमा, अर्थात् प्रमाज्ञानमिति प्रतिपादयन् निकृष्टलक्षणत्वेन तद्वन्निष्ठविशेष्यतानिरूपकत्वे सति तन्निष्ठप्रकारतानिरूपकत्वे सत्यनुभवत्व यथार्थानुभवस्य लक्षणमिति निष्कर्ष: प्रस्तुतो विद्यते त्रालेखे। किन्च वैशेषिकदर्शनदृष्ट्या उपमितिप्रमाया: शाब्दप्रमायाश चानुमान एवान्तर्भाव इत्यपि विषयोड त्र प्रस्तुतो विद्यते। अस्मान्निष्कर्षान्यायवैशेषिकशास्त्रजि ज्ञासूनां कृते तदभिमतप्रमाविषयस्य निकृष्टतया स्वरूप ज्ञा नार्थमुपयोगित्वं भविष्यतीत्यपेक्षते ।)

शब्दकुज्जी - प्रमा, प्रत्यक्षम, अनुमिति:, उपमिति:, शब्द्दः ।

\section{१. विषयपरिचय:}

जगत्यस्मिन् सन्ति बहूनि दर्शनानि। तन्मध्ये न्यायवैशेषिकयो: स्थानं विशिष्टं वर्तते। न्यायशास्त्रं हि महर्षिगौतमप्रणीत ज्चेद् वैशेषिकशास्त्रं महर्षिकणादप्रणीतमिति। न्यायवैशेषिकदर्शनसम्बद्धप्रमाविषयकचिन्तने सन्ति नैकविधा: समस्या: । तादृशसमस्यानां निराकरणायैव शोधलेखनेडस्मिन् प्रवृत्तिः । ज्ञानं हि द्विविधं स्मृत्यनुभवभेदेन । तत्र अनुभवस्य यथार्थायथार्थत्वेन भेददूयमित्यपि जेयम् । ज्ञानम, बुद्धि:, उपलब्धिश्चैते शब्दा: समानार्थका इति न्यायसूत्रकारस्य गौतमस्योद्घोषः। अनेन यथार्थज्ञानम, यथार्थबुद्धि: यथार्थोपलब्धिर्वा प्रमेति स्पष्टीभवति। सा च प्रमा तद्वति तत्प्रकारकानुभवरूपेति बहुशः प्रतिपादिता न्यायवैशेषिकशास्त्रे । अत एव न्याये वैशेषिके च प्रमाया: स्वरूपं कथं विवृतम् ? तद्भेदाश्च कथं प्रतिपादिता: ? प्रत्यक्षानुमित्युपमितिशाब्दाश्च किंस्वरूपा: ? इत्यादिसमस्यानां खलु समाधानाय प्रयत्नो विहितोऽत्रालेखे । न्यायाभिमतानां प्रत्यक्षानुमानोपमानशब्दादिप्रमाणानां कार्यजातानि प्रत्यक्षानुमित्युपमिति शाब्दात्मकज्ञानान्यथ च वैशेषिकाभिमतयो: प्रत्यक्षानुमानप्रमाणयो: कार्यभूतं प्रत्यक्षमनुमितिज्च विश्लिष्य 
वैशेषिकदर्शनदिशोपमिते: शाब्दस्य चानुमान एवान्तर्भावो भवतीति रीत्या निष्कर्षः प्रस्तुतो वर्तते । इदानीमत्रालेखे न्यायवैशेषिकदर्शनाभिताया: प्रमाया: स्वरूपप्रदर्शनपुरस्सरं तद्भेदाश्च विमृश्यन्ते ।

\section{२. अध्ययनविधि:}

प्रस्तुतमिदमनुसन्धानं मुख्यतया पुस्तकालयीयविधिमड्गीकृत्य विहितम् । अत्र न्यायवैशेषिकदर्शनसम्बद्वेभ्य: संस्कृतमूलाकरग्रन्थेभ्य:, एतद्विषयसम्बद्वेभ्यो ग्रन्थान्तरेभ्यश्च सामग्री: सङुलय्य तासां सामग्रीणामुत प्रमाविषयकचिन्तनानां विश्लेषणं च कृत्वा निष्कर्ष: प्रस्तुतो वर्तते ।

\section{३. अध्ययनस्य क्षेत्रं सीमाङ्कनन्च}

न्यायवैशेषिकदर्शनसम्बद्धप्रमास्वरूपस्य तद्भेदानां चाध्ययनमेवास्यानुसन्धानात्मकस्यालेखस्य मुख्यं क्षेत्रमस्ति । न्यायवैशेषिकाचार्यै: न्यायभाष्य-प्रशस्तपादभाष्य-न्यायसिद्धान्तमुक्तावल्यादिग्रन्थेषु कृतस्य प्रमालक्षणस्य, तद्भेदानां (प्रत्यक्ष-अनुमिति-उपमिति-शाब्दानाम्) च विवेचनमाहोस्विद् विश्लेषणमेवास्य खल्वनुसन्धानात्मकालेखस्य मूलं क्षेत्रं सीमा च वर्तते ।

४. सैद्धान्तिकाधार:

आलेखेडस्मिन् न्यायवैशेषिकदर्शनसम्बद्धग्रन्थानुसारं प्रमाविषयकचिन्तनं विश्लेषितं वर्तते । न्यायवैशेषिकगतसंस्कृतमूलाकरा ग्रन्था:, एतद्विषयसम्बद्धा व्याख्यानात्मका ग्रन्थाश्च प्रस्तुतस्यानुसन्धानात्मकालेखस्य सैद्धान्तिकाधारत्वेन परिगणिता विद्यन्ते । विशेषतोऽस्मिन् अनुसन्धानात्मकालेखे न्यायसूत्रम, न्यायभाष्यम्, न्यायवार्तिकम, न्यायवार्तिकतात्पर्यटीका, न्यायकुसुमाज्जलि:, वैशेषिकसूत्रम,, प्रशस्तपादभाष्यम, वैशेषिकसूत्रोपस्कारः, कारिकावली, न्यायसिद्धान्तमुक्तावली, तर्कभाषा, तर्कसड्ग्रहश्चेत्यादिग्रन्था: सैद्धान्तिकाधारत्वेनाड्गीकृताः । एतादृशसैद्धान्तिकाधारे प्रमास्वरूपं तद्भेदाज्च विविच्य निष्कर्ष: प्रस्तुतो विद्यते। अस्यानुसन्धानात्मकालेखस्य व्यवस्थितरूपेण स्वरूपनिर्माणप्रसड्गे प्रचलिताया: (एपीए) पद्धतेरवलम्बनं कृतं वर्तते।

\section{२. विश्लेषणप्रक्रिया}

प्रमास्वरूपं तद्भेदाश्चेति शीर्षके केन्द्रीभूयास्यानुसन्धानात्मकालेखस्य व्यवस्थितरूपेण परिसमाप्त्यर्थं सर्वप्रथमन्तावद् न्यायवैशेषिकदर्शनसम्बद्धग्रन्थानां चयनं कृतम्। तत्र प्रमाविषयकचिन्तनकमे हि न्यायवैशेषिकाचार्यै: स्वीकृतप्रमास्वरूपं प्रदर्श्य प्रत्यक्षानुमित्युपमितिशाब्दरूपप्रमाभेदस्य च विश्लेषणं विहितं वर्तते।

\section{६. प्रमास्वरूपम्}

का नाम प्रमा ? किन्तत्स्वरूपम् ? इत्यत्र न्यायवैशेषिकाचार्ये: प्रतिपादितप्रमाया: तत्स्वरूपस्य च विवेचनं प्रस्तुतं वर्ततेऽत्र। सर्वप्रथमन्तावत् प्रमास्वरूपज्ञानात्पूर्वं ज्ञानस्य भेदोऽवगन्तव्यो भवति। ज्ञानं हि द्विविधं स्मृत्यनुभवभेदेनेति । स्मृतिर्नाम संस्कारमात्रजन्यत्वे सति ज्ञानत्वमिति । तद्भिन्नं ज्ञानमनुभव इति । तादृशानुभवस्यापि यथार्थायथार्थभेदेन द्वैविध्यमित्यपि जेयम् । तयोर्मध्ये यथार्थानुभवो यः, सैव प्रमेत्युच्यते । तत्र कैश्चिदाचार्यै: साक्षात्प्रमाया लक्षण विहितज्चेत् कैश्चिदाचार्यै: प्रमाणलक्षणगतप्रमाज्ञापकपदेन तल्लक्षणं 
विहितं वर्तते । तच्च यथाक्रमं प्रस्तूयते-

महर्षिणा गौतमेन न्यायसूत्रे साक्षात् प्रमालक्षणं नोक्तम्।तथापि “प्रमाणप्रमेयसंशयप्रयोजनसिद्धान्तावयवतर्कनिर्णयवादजल्पवितण्डाहेत्वाभासच्छलजातिनिग्रहस्थानानां तत्त्वज्ञानाद् नि:श्रेयसाधिगमः" (न्यायसूत्रम्, १-१-१) इति प्रथमसूत्रे तत्त्वज्ञानस्य नि:श्रेयसोपायत्वं प्रदर्श्य "दुःखजन्मप्रवृत्तिदोषमिथ्या ज्ञानानामुत्तरोत्तरापाये तदनन्तरापायादपवर्गः" (न्यायसूत्रम,१-१-२) इति द्वितीयसूत्र तत्त्वज्ञानस्य मिथ्याज्ञाननिवर्तकत्वप्रतिपादनेन किल तत्त्वज्ञानं प्रमेति सूत्रकाराशयः ज्ञापितो भवति। तथा च मिथ्याज्ञानं भ्रमः। तादृशमिथ्याज्ञाननिवर्तक न्च ज्ञानं प्रमेति व्यवहरन् सूत्रकारः प्रमास्वरूपं स्वीकरोति। न्यायभाष्ये वात्स्यायनेन प्रमास्वरूपं प्रदर्शयितुम् "उपलब्धिसाधनानि प्रमाणानीति समाख्यानिर्वचनसामर्थ्याद् बोद्धव्यम्" (वात्स्यायन:, सन् १९९६, १६) इत्युच्यते। उपलब्धेर्यत् साधनं तत् प्रमाणं भवतीत्यनेन वात्स्यायनवाक्येन उपलब्धिरेव प्रमा भवतीत्यवगम्यते। "बुद्धिरूपलब्धिर्जानमित्यनर्थान्तरम्" (न्यायसूत्रम्, १-१-१५) इत्यनेन न्यायसूत्रेणोपलब्धिपदं ज्ञानार्थपरकमिति लभ्यते। निर्विषयकज्ञानस्यासम्भवादर्थविषयकज्ञानत्वमेव प्रमात्वमिति लक्षणं लभ्यते। अत एव न्यायभाष्ये वात्स्यायनेन प्रमाणादिभिर्जन्यं यदात्मसमवेतं यथार्थज्ञानमेव प्रमितिरित्युक्तम्। तदुक्त ज्च "यदर्थविज्ञानं सा प्रमितिः" (वात्स्यायनः, सन् १९९६, ३) इति ।

न्यायवार्तिके उद्योतकरेणापि "उपलब्धिहेतु: प्रमाणम, उपलब्धिहेतुत्वं प्रमाणत्वम, यदुपलब्धिनिमित्तं तत् प्रमाणम्” (उद्योतकर:, सन् २००७, $y$ ) इत्यर्थविषयकज्ञानत्वमेव प्रमात्वमुत, उपलब्धिरेव प्रमेत्येवं प्रमास्वरूपमभीष्टम् । वाचस्पतिमिश्रस्तु न्यायवार्तिकतात्पर्यटीकायां “प्रमासाधनं हि प्रमाणम् । न च स्मृति: प्रमा। लोकाधीनावधारणो हि शब्दार्थसम्बन्धः। लोकश्च संस्कारमात्रजन्मन: स्मृतेरन्यामुपलब्धिमर्थाव्यभिचारिणीं प्रमामाचष्ट" (मिश्र:, सन् २०१३, २१) इत्येवंरीत्या प्रमां निरूपयति। तात्पर्यटीकाकारस्याशयस्त्वेवं वर्ततेयद्यर्थविषयकज्ञानत्वमुत उपलब्धिहेतुत्वमेव प्रमात्वमुच्यते, तर्हि स्मृतिरूपोपलब्धिहेतो: संस्कारस्यापि प्रामाण्यापत्तिः अर्थात् संस्कारस्यापि प्रमात्वं स्यान्नाम । एतादृशदोषनिवारणाय वाचस्पतिमिश्रेण प्रमाया: साधनं प्रमाणमित्यभिमतम्। सा च प्रमा अर्थाव्यभिचारिस्मृतिभिन्नज्ञानरूपेति। ज्ञानस्यार्थाव्यभिचारित्वन्नाम यथावस्थितार्थविषयकत्वम्। एतावता यथावस्थितार्थविषयकत्वे सति ज्ञानत्वं प्रमाया लक्षणमिति सिद्धयति। जरन्नैयायिकेन जयन्तभट्टेन न्यायमज्जयां “कर्तृकर्मविलक्षणा संशय-विपर्यय-रहितार्थावबोधविधायिनी बोधाबोधस्वभावा सामग्री प्रमाणम्" (भट्ट:, सन् १९६४, २३) इति प्रमाणलक्षणं कृतम्। एतेन संशयभिन्नो विपर्ययभिन्नश्च योऽर्थबोध:, सा प्रमेत्यवगम्यते । अत्र संशयविपर्ययभिन्नत्वे सति अर्थविषयकज्ञानत्वस्य तर्के विद्यमानत्वादतिव्याप्तिः । एवमेव स्मृतावपि उक्तलक्षणस्य गमनादतिव्याप्तिः दुर्वरैवातस्तद्वारणाय जयन्तेन अव्यभिचारिणीम, असन्दिग्धाम, अर्थोपलब्धिन्च विदधती बोधाबोधस्वभावा सामग्री प्रमाणमित्यपि प्रतिपादितम् । एतेन अव्यभिचारिणी संशयभिन्ना चार्थोपलब्धिरेव प्रमेति ज्ञातं भवति। उदयनाचार्येण "यथार्थानुभवो मानमनपेक्षतयेष्यते" (न्यायकुसुमाज्जलिः, ४-१) इत्यनया कारिकया प्रमा निरूपिता वर्तते । अनेन खलु यथार्थानुभवत्वं प्रमात्वमिति सिद्धयति। किन्च "मितिः सम्यक्परिच्छित्तिस्तद्वत्ता च प्रमातृता" 
(न्यायकुसुमाज्जलि:, $४-y$ ) इत्यनया कारिकया सम्यगनुभवत्वमेव प्रमात्वमिति स्पष्टीभवति ।

वैशेषिकदर्शने विद्यैव प्रमात्मकं ज्ञानमिति प्रतिपादितम् । तदुक्त ज्च कणादेन "अदुष्टं विद्या" (वैशेषिकसूत्रम्, ९-२-१२)। दोषरहितं ज्ञानमेव विद्या (प्रमा) भवतीत्यर्थः । अस्यैव सूत्रस्यार्थं प्रतिपादयन् शंकरमिश्रो वैशेषिकसूत्रोपस्कारे भणति यत्- "अदुष्टमदुष्टेन्द्रयजन्यं यत्र यदस्ति तत्र तदनुभवो वा समानाधिकरणप्रकारानुभवो वा विशेष्यावृत्त्यप्रकारकानुभवो वा विद्येत्यर्थः" (मिश्र:, सन् १९६९, प१६) इति। अनेन व्याख्यानेन दोषरहितं यद् दोषरहितेन्द्रियजन्यज्ञानमेव विद्याया उत प्रमाया लक्षणमित्यर्थोऽ वबोध्यते । विश्वनाथेन प्रमाया लक्षणदूयं प्रस्तुतं विद्यते । तत्र “..... भ्रमभिन्नन्तु ज्ञानमत्रोच्यते प्रमा" (भट्टाचार्य:, सन् २००३ : कारिका-१३४) इत्येक लक्षणम् । भ्रमभिन्नं यज्ञानं तदेव प्रमेत्युच्यते चेत् शुक्तिरजतयो: 'इमे रजते' इत्याकारके समूहालम्बनज्ञाने शुक्त्यंशे प्रमात्वाभावेडपि रजतांशेडपि प्रमात्वाभावापत्तिः स्यादेव, अर्थात् तादृशसमूहालम्बनज्ञानघटकरजतांशे प्रमात्वेन प्रतीतिर्न स्यादतो द्वितीयलक्षणं प्रस्तुतम् । तदुक्तः्च - "अथ वा तत्प्रकारं यज्ञानं तद्व्विशेष्यकम, तत्प्रमा" (भट्टाचार्यः, सन् २००३, कारिका-१३५) इति ह्यपरलक्षणम् । तथा च तद्विश्वेष्यकत्वे सति तत्प्रकारकत्वे सति ज्ञानत्वं प्रमाया लक्षणमिति फलितम् । शुक्तिरजतयो: 'इमे रजते' इत्याकारके समूहालम्बनज्ञाने शुक्तित्ववच्छुक्तिविशेष्यकशुक्तित्वप्रकारक ज्ञानाभावेडपि रजतत्ववद्रजतविशेष्यकरजतत्वप्रकारकज्ञानस्य विद्यमानत्वाद् लक्षणसमन्वय: ।

एवज्च "तद्वति तत्प्रकारकोडनुभवो यथार्थः। सैव प्रमेत्युच्यते। यथा - रजते इदं रजतमिति ज्ञानम्" (भट्टः, सन् २०१७, १२४) इत्येवंप्रकारेणान्नम्भट्टेन प्रमा निरूपिता । तर्कभाषाकारोऽपि "यर्थार्थानुभव: प्रमा" (मिश्र:, सन् २००३, १६) इत्येवंरीत्या प्रमां निरूपितवान्। साकल्येनेदं वक्तु शक्यते यत्- रजतं दृष्ट्वा इदं रजतमिति ज्ञानम्, अर्थात् रजतत्ववति रजते रजतत्वप्रकारकानुभव: प्रमा भवतीति।

अत्रेदं ज्ञेयम्- वस्तुतस्तु तद्वन्निष्ठविशेष्यतानिरूपकत्वे सति तन्निष्ठप्रकारतानिरूपकत्वे सत्यनुभवत्वं यथार्थानुभवस्य लक्षणमिति हि निकृष्टलक्षणं बोध्यम् । 'रजते इदं रजतम्' इत्यत्र लक्षणसमन्वयश्चेत्थं प्रदर्श्यते- तदूति=रजतत्ववति रजते, तत्प्रकारक:=रजतत्वप्रकारकः, योऽनुभव:, स यथार्थ इति । अत्र तत्पदेन प्रकारीभूतो धर्मो ग्राहयः । एवज्च तत् रजतत्वम, तदूत् रजतम् । तथा च रजतत्ववद्रजतनिष्ठविशेष्यतानिरूपकत्वे सति रजतत्वनिष्ठप्रकारतानिरूपकत्वे सत्यनुभवत्वं 'रजते इदं रजतम्' इत्याकारकज्ञाने वर्तत इति लक्षणसमन्वयः । अत्र तद्वन्निष्ठविशेष्यतानिरूपकत्वे सतीति पदं न निवेश्यते चेत् 'शुक्तौ इदं रजतम्' इत्याकारके भ्रमात्मके ज्ञाने रजतत्वनिष्ठप्रकारतानिरूपकत्वे सत्यनुभवत्वस्य विद्यमानत्वादतिव्याप्तिः । अतस्तद्वारणाय प्रथमदलं देयम्। तथा च 'शुक्तौ इदं रजतम्' इत्याकारके भ्रमात्मके ज्ञाने रजतत्ववद्रजतनिष्ठविशेष्यतानिरूपकत्वाभावेन नातिव्याप्तिः।

अत्र हि रजतत्वाभाववच्छुक्तिनिष्ठविशेष्यतानिरूपकत्वं वर्तते, न तु रजतत्ववद्रजतनिष्ठविशेष्यता। एवज्च द्वितीयदलाभावे ‘शुक्तौ इदं रजतम्' इत्याकारके भ्रमात्मके ज्ञान एव शुक्तित्ववच्छुक्तिविशेष्यकत्वसत्त्वात्, 
एवमेवानुभवत्वस्यापि विद्यमानत्वादतिव्याप्तिः । तद्वारणाय तन्निष्ठप्रकारतानिरूपकत्वे सतीति द्वितीयदलमपि निवेश्यम् । तथा च 'शुक्तौ इदं रजतम्' इत्याकारके भ्रमात्मके ज्ञाने शुक्तित्ववति शुक्तौ रजतत्वनिष्ठप्रकारतानिरूपकत्वसत्त्वेन शुक्तित्वनिष्ठप्रकारतानिरूपकत्वाभावेन नातिव्याप्तिः । एवमेव लक्षणघटकानुभवत्वमात्रोक्तौ ‘शुक्तौ इदं रजतम्' इत्याकारकायथार्थानुभव एवातिव्याप्तिर्दुर्वारैव । अतस्तद्वारणाय प्रथमदलं लक्षणे निवेशनीयमित्यपि जेयम् ।

नन्वेवं सत्यपि ‘रड्गररजतयोरिमे रजतरड्गे’ इत्याकारके समूहालम्बनात्मके भ्रमज्ञाने रड्गत्ववद्रड्गस्य रजतत्ववद्रजतस्य चोभयोर्विशेष्यत्वेन रड्गत्वरजतत्वयो: खलु प्रकारत्वेन चातिव्याप्तिर्दुवारा । तादृशदोषवारणाय तद्वन्निष्ठविशेष्यतानिरूपिततन्निष्ठप्रकारताशालित्वे सत्यनुभवत्वमिति हि वक्तव्यं भवति। तथा चात्र रड्गनिष्ठविशेष्यतानिरूपिता रड्गत्वनिष्ठप्रकारता न भवति, किन्तु रजतत्वनिष्ठप्रकारतैव भवतीति नातिव्याप्तिः। अत्र समूहालम्बनं नाम नानाविशेषणविशेष्यकज्ञानरूपं बोध्यम्।

इदानीन्तावद् दर्शनेष्वाचार्यै: स्वातन्त्र्येण कति प्रमा स्वीक्रियत इत्यत्र विचार्यते- तथा च प्रत्यक्षमेकमेव प्रमेति चार्वाका:, प्रत्यक्षानुमितिभेदेन प्रमाया: द्वैविध्यमिति बौद्धा: वैशेषिकाश्च, प्रत्यक्षानुमित्युपमितिभेदेन प्रमात्रयमिति नैयायिकैकदेशिन:, प्रत्यक्षानुमित्युपमितिशाब्दभेदेन प्रमाचतुष्टयमिति नैयायिका:, प्रत्यक्षानुमित्युपमितिशाब्दार्थापत्तिभेदेन प्रमाया: पञ्चत्वमिति प्राभाकरा:, अनुपलब्धिमप्यादाय प्रमाया: षड्विधत्वमिति भाट्टवेदान्तिनौ, सम्भवैतिद्यावपि संगृट्याष्टौ प्रमेति पौराणिका:, चैष्टिकमप्यादाय प्रमाया नवविधत्वमिति तात्त्रिका इत्यपि स्मर्तव्यम्। सम्प्रति प्रमास्वरूपविवेचनानन्तर प्रमाभेदा: प्रदर्श्यन्ते-

\section{६.१ प्रमाभेदा:}

न्यायदर्शने प्रत्यक्षानुमित्युपमितिशाब्दभेदेन प्रमायाशचतुष्ट्वं स्वीक्रियते चेद् वैशेषिकदर्शने प्रत्यक्षानुमितिभेदेन प्रमादूयं स्वीक्रियते । एवज्चेदानीं न्यायोक्तप्रमाचतुष्टयस्य वैशेषिकोक्तप्रमादूयस्य च विवेचनमधस्तात् प्रस्तूयते-

\section{६.१.१ प्रत्यक्षम् (ज्ञानम्)}

प्रत्यक्षप्रमाणजन्यं ज्ञानं हि प्रत्यक्षम् । तच्चेन्द्रियस्यार्थस्य च सन्निकर्षेणोत्पद्यमानं ज्ञानमेवेति । इन्द्रियन्च चक्षुरादिकम् । अर्थो घटादिः। तयो: सन्निकर्षो नाम संयोगादिसम्बन्धः । तादृशसन्निकर्षजन्यं यज्ञानं तत्प्रत्यक्षमिति । प्रत्यक्षशब्दस्य प्रमाप्रमाणयोश्चोभयार्थे प्रयोगो भवति । तन्नाम प्रत्यक्षप्रमाया: करणमपि प्रत्यक्षप्रमाणं भवति। गौतमेन "इन्द्रियार्थसन्निकर्षोत्पन्न ज्ञानमव्यपदेश्यमव्यभिचारि व्यवसायात्मक प्रत्यक्षम्” (न्यायसूत्रम, १११८४) इत्युक्तम्। सूत्रार्थस्तु इन्द्रियस्यार्थस्य च सन्निकर्षेणोत्पन्नं यदव्यपदेश्यम्=शाब्दबोधभिन्नम,, अव्यभिचारि=भ्रमभिन्नम, व्यवसायात्मकम्=निश्चयात्मकं संशयभिन्नं वा यज्ञानं तत् प्रत्यक्षमिति ।

सूत्रमिदमर्थापयन् वात्स्यायन “इन्द्रियस्यार्थेन सन्निकर्षादुत्पद्यते यज्ञानं तत्प्रत्यक्षम्” (वात्स्यायनः, सन् १९९५, २०) इति वदति । प्रत्यक्षमिति पदन्तु अव्ययीभावसमासात् सिद्धचति । प्रत्यक्षशब्दस्य 
व्युत्पत्ति कुर्वन् न्यायभाष्यकारो वदति यत्- "तच्च-अक्षस्य अक्षस्य प्रतिविषयं वृत्तिरिति । वृत्तिश्च सन्निकर्षो ज्ञानं वेति" (वात्स्यायन: सन् १९९५, १७)। प्रशस्तपादस्त्वेवं वदति- "अविद्यापि चतुर्विधा । प्रत्यक्षलैड़िग्गकस्मृत्यार्षलक्षणा । अक्षमक्षं प्रतीत्योत्पद्यत इति प्रत्यक्षम्” (देवाचार्यः, सन् २०१६, १५३) इति। एतन्मते विद्या चतुर्विधा । शड्करमिश्रोऽपि विद्याया: चातुर्विध्यमेवाड्गीकरोति (मिश्र:, सन् १९६९, ४५०) । वैशेषिकराद्धान्ते विद्यायाशचातुर्विध्यं स्वीक्रियते, परन्तु नैयायिकैस्तन्न स्वीक्रियते । अतः प्रत्यक्षलैड्गिकभेदादिति द्वैविध्यमेव ।

न्यायवार्तिककारेण तु "इन्द्रियेणार्थस्य सन्निकर्षादुत्पद्यते यज्ञानं तत्प्रत्यक्षम्" (उद्योतकरः, सन् १९९७, ३०) इत्युच्यते। अन्नम्भट्टेनापि इन्द्रियार्थसन्निकर्षोत्पन्नं ज्ञानमेव प्रत्यक्षमिति लक्षणं प्रस्तुतम् । इन्द्रियपदेन बाह्यज्ञानेन्द्रियातिरिक्त मनसोऽपि ग्रहणं कर्तव्यम्। मानसप्रत्यक्षेऽपीन्द्रियददेन मनस एव ग्रहणं भवति। सामान्यतो बाह्यप्रत्यक्षे त्रिविधः सन्निकर्षो भवति- आत्मनो मनसा सह सन्निकर्ष: मनसो ज्ञानेन्द्रयेण सह सन्निकर्ष:, ज्ञानेन्द्रियस्य बाह्यपदार्थेन सह सन्निकर्षश्चेति। मानसप्रत्यक्षे तु द्विविधः सन्निकर्षो भवतिआत्मनो मनसा सह सन्निकर्ष: मनस: मनोभावेन सह सन्निकर्षश्चेति। ननु इन्द्रियार्थसन्निकर्षोत्पन्नं ज्ञानं प्रत्यक्षमिति व्यभिचरितम् । तथाहि सोपनेत्रचक्षुरिन्द्रियेण पदार्थस्य ग्रहणं कथम् ? यतश्चक्षुरिन्द्रियस्य साक्षात्पदार्थेन सह संयोगाभावादिति प्रश्ने यदि स्वच्छद्रव्यं विद्यते चेत्तस्य तेजसो निरोधकत्वाभावात्तदन्तः चक्षुरिन्द्रियस्य प्रवेशसम्भवात् चक्षुरिन्द्रियेण सहजतयैव प्रत्यक्षसम्भवाच्च न कोऽपि दोषः । कणादमते इन्द्रियार्थसन्निकर्ष: इन्द्रियन्च प्रत्यक्षप्रमाणपदवाच्यम् । इन्द्रियार्थसन्निकर्षजन्यत्वे सति ज्ञानत्वं प्रत्यक्षस्य लक्षणम् । लक्षणेडस्मिन् ज्ञानत्वमात्रोक्तौ अनुमित्यादावतिव्याप्तिः । ज्ञानत्वपदाभावे ध्वंसं प्रति प्रतियोगिन: कारणत्वेन इन्द्रियार्थसन्निकर्षध्वंसेडपि इन्द्रियार्थसन्निकर्षजन्यत्वस्य सत्वात्तत्रातिव्याप्तिः। अतस्तद्वारणाय विशेष्यविशेषणपदं देयम् ।

किन्च जीवात्मा परमात्मभिन्न इत्यात्मविषयकानुमितौ प्रकृतज्ञानविषयत्वस्याप्यात्मानि विद्यमानत्वेन पुनरपि तत्रैवात्मन्यतिव्याप्तिरिति चेन्न, तत्र तावद् इन्द्रियार्थसन्निकर्षत्वावच्छिन्नजनकतानिरूपितजन्यतावच्छेदकीभूत-ज्ञानत्वभिन्नजातिमत्त्वस्य लक्षणत्वस्वीकारादिति। इदानीमिन्द्रियार्थसन्निकर्षपदेन आत्ममनस्संयोगस्य ग्रहणेऽपि तज्जन्यतावच्छेदकीभूतजातिः ज्ञानत्वभिन्ना न, नापीन्द्रियार्थसन्निकर्षजन्यतावच्छेदिकेत्यतो न तत्रातिव्याप्तिः। ईश्वरप्रत्यक्षस्य खलु नित्यतया जन्यत्वाभावेन तत्राव्याप्तिरिति चेन्न, तत्र जन्यप्रत्यक्षस्यैव खलु लक्षणं कृतन्न तु ईश्वरप्रत्यक्षस्येति। अथवा ज्ञानाकरणकं ज्ञानं प्रत्यक्षमिति स्वीकारे ईश्वरप्रत्यक्षे नाव्याप्तिः। अनुमितौ व्याप्तिज्ञानस्य, उपमितौ सादृश्यज्ञानस्य, शाब्दबोधे पदज्ञानस्य, स्मृतौ अनुभवस्य कारणत्वात्तत्र तत्र नातिव्याप्तिः। इदं लक्षणं हीश्वरप्रत्यक्षसाधारणम् ।

प्रत्यक्षं द्विविधं निर्विकल्पकसाविकल्पकभेदात् । तदुक्तन्च "तद् द्विविधं सविकल्पक निर्विकल्पकन्च। तत्र निष्प्रकारक ज्ञानं निर्विकल्पकम् । यथेदं किज्चित् । सप्रकारक ज्ञानं सविकल्पकम् । यथा डित्थोडयम, ब्राह्मणोऽयम्, श्यामोऽयमिति" (भट्टः, सन् २०१७, १५७७) इति । वैशेषिका अपि प्रत्यक्षस्य द्वैविध्यं 
स्वीकुर्वन्ति । यथोक्त वैशेषिकसूत्रोपस्कारे- "असर्वज्ञीयन्च प्रत्यक्षं द्विविधम्- सविकल्पक निर्विकल्पक न्च" (मिश्र:, सन् १९६९, ४५१) इति ।

अत्रेदं बोध्यम्- प्रकारत्वानिरूपकत्वे सति ज्ञानत्वं निर्विकल्पकस्य लक्षणम् । 'इदं किज्चिदि'ति ज्ञाने विशेषणरहितं ज्ञानं जायतेडतो निर्विकल्पकम्। वस्तुतो नामजात्यादिरहितं विशेष्यज्ञानं विना 'इदं किज्चिदि' त्याकारकं ज्ञानं भवति चेत्तद् निर्विकल्पकमिति। प्रकारतानिरूपकत्वे सति ज्ञानत्वं सविकल्पकस्य लक्षणम् । यथा श्यामोऽयम, घटोऽयम् इति। घटोऽयमित्यत्र घटत्वविशिष्टघटस्य ज्ञानेनेदं सविकल्पकमिति जेयम् । अत्र हि घटं दृष्ट्वा घटत्वप्रकारकघटविशेष्यकज्ञानं भवति, अतः सविकल्पकम्। 'श्यामोऽयम्' इत्यत्र श्यामत्वविशिष्टश्यामस्य ज्ञानेन सविकल्पकमिति। अत्र श्यामत्वप्रकारकश्यामविशेष्यकज्ञान भवति, अतः सविकल्पकमिति ।

एकसम्बन्धिज्ञानमपरसम्बन्धिस्मारकं भवतीति नियमेन पदार्थस्वरूपज्ञानं यदा, तदनन्तरं नामजात्यादिस्मरणमपि तस्य भवति। इदं ज्ञानमपि सविशेषमेव भवति। सविकल्पकज्ञाने वस्तु सविशेषं सदेव भासते, अर्थाद् विशेष्यविशेषणभावसम्बन्धसहितमेव ज्ञानमुत्पद्यते। सर्वत्रापि प्रत्यक्षप्रमाणविषये ज्ञातु: सर्वप्रथमं बाह्येन्द्रियेण निश्चयरूपं ज्ञानं जायते। अन्तःकरणेन निश्चयात्मकज्ञानानन्तरमनुव्यवसायात्मकं ज्ञानं जायते। यस्य बाह्येन्द्रियं नष्टं तस्यानुव्यवसायात्मकं ज्ञानं न सम्भवति, अर्थादन्धस्य बधिरस्य वा न कदाप्यनुव्यवसायात्मकज्ञानं भवति। अतस्तत्पूर्वं व्यवसायात्मकज्ञानस्योत्पादने चक्षुरादिबाह्येन्द्रियाणां खलु अपेक्षा भवति।

इदमत्र गाढं चिन्तनीयम्- निष्प्रकारकं ज्ञानं निर्विकल्पकमित्यत्र विशेषणमेव प्रकार इति। तथा च प्रकारताशून्यं ज्ञान निर्विकल्पकमिति पूर्वमुक्तम् । यस्मिन् ज्ञाने न किमपि विशेषणं भवति, तदेव निर्विकल्पकमिति। सर्वमपि ज्ञानं सदा सविषयकमेव भवति। नहि कदापि ज्ञानं निर्विषयक भवति। अत एव ज्ञानं सर्वदापि विषयि भवति। तादृशज्ञाने भासमानपदार्था विषया भवन्ति। यथा 'अयं घटः' इत्यादिज्ञाने भासमानो घटादि: विषय उच्यते । तादृशघटादिनिष्ठविषयता त्रिविधा भवति- प्रकारताख्यविषयता, विशेष्यताख्यविषयता, संसर्गताख्यविषयता चेति । तत्र चोदाहरणम्- 'अयं घट:' इत्याकारकज्ञाने घटो विषय:, ज्ञानं च विषयि भवति। एवमेव घटो विशेष्य:, घटत्वन्तु विशेषणं प्रकारो वेति । अत एव घटत्वप्रकारकघटविशेष्यकं ज्ञानं तत्र जायते । त्रिसृषु विषयतासु प्रकारीभूते घटत्वे प्रकारताख्यविषयता वर्तते। विशेष्यीभूते घटे तु विशेष्यताख्यविषयता विद्यते। घटत्वं हि घटे तिष्ठति। तत्र च कश्चन सम्बन्धो वक्तव्यः। स सम्बन्धस्तु न संयोग:, कुतः ? द्रव्ययोरेव संयोग इति नियमात् । जातिव्यक्त्यो: समवाय इति नियमेन घटघटत्वयो: सम्बन्व: समवायो वक्तव्य:, नान्य:।

एवज्च घटघटत्वयो: समवायसंसर्गे प्राप्ते संसर्गताख्यविषयता तत्र वर्तते। तथा च विशेष्यतानिरूपकं ज्ञानम, प्रकारतानिरूपक ज्ञानं साविकल्पकमित्यादिलक्षणमपि कर्तु शक्यते। 'अयं घट:' इत्याकारकज्ञानमेव न स्याच्चेत्रार् ज्ञानं विषयि न भवेत्। घटोऽपि विषयो न कस्यापि भवेदित्यपि ज्ञातव्यम्। निर्विकल्पकज्ञानस्य नामजातिसंज्ञेत्यादियोजनारहितत्वात् तत्र त्रिसृषु विषयतासु मध्ये न कापि विषयता वक्तुं शक्यते तस्तत्र 
निर्विकल्पके चतुर्थी विषयतेति कल्पते। एवंरीत्या न्यायवैशेषिकदर्शनाभिमतप्रत्यक्षप्रमा, तद्भेदाश्च प्रतिपादिताः।

\section{६.१.२ अनुमितिः}

इदानीं प्रत्यक्षप्रमाविचारानन्तरमनुमितिप्रमा विचार्यते । किन्नामानुमितिः ? इत्यत्रोच्यते"परामर्शजन्यं ज्ञानमनुमितिः" (भट्टः, सन् २०१७, १७४) इति। परामर्शजन्यं यज्ञानं सैवानुमितिः । यथा महानसादौ किल वहनेः धूमस्य च सर्वथा साहचर्यं दृष्ट्वा कदाचित् कुत्रचन पर्वते एकस्य धूमस्य (व्याप्यस्य) दर्शनेनान्यस्य वहनेः (व्यापकस्य) यज्ञानं जायते, तादृशज्ञानमेवानुमितिरिति । अनुमितित्वन्नाम परामर्शजन्यत्वे सति ज्ञानत्वमिति । 'पर्वतो बहिनमान्' इत्याकारकानुमितौ 'वहित्याप्यधूमवान् पर्वत:' इत्याकारकपरामर्शजन्यत्वस्याथ च ज्ञानत्वस्यापि सत्वाल्लक्षणसमन्वयः । अत्र ज्ञानत्वमात्रोक्तौ प्रत्यक्षादिज्ञाने तिव्याप्तिः। परामर्शजन्यत्वमात्रोक्तौ परामर्शध्वंसेडतिव्याप्तिः। परामर्शजन्यत्वं यथानुमिति:, तदूत् परामर्शध्वंसोऽपि । यतो हि परामर्शस्यैवाभावे कस्य ध्वंसो भवेत् ? ध्वंसं प्रति प्रतियोगिनः कारणत्वनियमात् । तस्मात् परामर्शध्वंसस्यापि परामर्शजन्यत्वादतिव्याप्तिः। तद्वारणाय ज्ञानत्वमित्यपि पदं देयम् । तथा सति नातिव्याप्तिः । कुतः ? परामर्शध्वंसस्य परामर्शजन्यत्वेपि ज्ञानत्वाभावादिति । अत्र प्रश्न: - परामर्शविषयकानुव्यवसाये परामर्शजन्यत्वस्य ज्ञानत्वस्य च विद्यमानत्वादतिव्याप्तिः । तत्र ज्ञानविषयक ज्ञानमनुव्यवसाय इत्युच्यते । मानसप्रत्यक्षात्मक: खलु अनुव्यवसायः । 'अयं पट:' इत्याकारकप्रत्यक्षानन्तरं 'अयं पटः इत्याकारकज्ञानवान् अहम्' इत्याकारकोऽनुव्यवसायः समुत्पद्यते । अनुव्यवसायं प्रति व्यवसायज्ञानस्य कारणत्वात् 'वहिनव्याप्यधूमवान् पर्वतः' इत्याकारकपरामर्शानन्तरं जायमाने 'वहित्याप्यधूमवान् पर्वत इत्याकारकज्ञानवान् अहम्' इत्यनुव्यवसाये परामर्शजन्यत्वस्य विद्यमानत्वेनातिव्याप्तिः । तद्वारणायानुमितिलक्षणे हेत्वविषयकत्वे सतीति पदं निवेश्यम् । तथा च लक्षणं भवति- हेत्वविषयकत्वे सति परामर्शजन्यत्वे सति ज्ञानत्वमनुमितेर्लक्षणमिति। परामर्शः किल हेतुविषयकः । अतः परामर्शानुव्यवसायोऽपि हेतुविषयक:। तथा च परामर्शानुव्यवसाये हेतुविषयकत्वस्यैव सत्तवाद् हेत्वविषयकत्वाभावान्नातिव्याप्तिः। ननु परामर्शो नाम क: ? उच्यते, "व्याप्तिविशिष्टपक्षधर्मता ज्ञानं परामर्शः" (भट्टः, सन् २०१७ : १७४) इति । किज्च-

"व्याप्यस्य पक्षवृत्तित्वधी: परामर्श उच्यते" (भट्टाचार्य:, सन् २००३, कारिका-६६)। अस्यार्थस्तु- व्याप्तिनिष्ठप्रकारतानिरूपकत्वे सति पक्षसम्बन्धविषयकत्वे सति ज्ञानत्वं परामर्शस्य लक्षणम् । 'वहिन्याप्यधूमवान् पर्वतः' इत्याकारकपरामर्शज्ञाने व्याप्तिः (धूम:) विशेषणं वर्तते । तथा च व्याप्तिनिष्ठप्रकारतानिरूपकत्वं ज्ञानस्येति। यत्र विशेषणविशेष्यावगाहिज्ञान तत्र तयो: संसर्गो किल नियमेन भासते। एवज्च धूमस्य पर्वतांशे विशेषणत्वेन धूमपर्वतयो: संसर्गस्य संयोगस्यापि विषयत्वात् पक्षसम्बन्धविषयकत्वज्ञानत्वमपि परामर्शे विद्यत इति लक्षणसमन्वयः।

अनुमित्युत्पत्तिक्रमस्तु एवम्- प्रथमन्तावद् महानसादौ धूमं वहिनं च पश्यन् तयो: खलु साहचर्यं गृहीत्वा पुनस्तयोर्भूयोदर्शनेन व्यभिचाराभावं च गृहीत्वा 'यत्र यत्र धूमस्तत्र तत्र वहिन'रिति धूमे वहिनिरूपितां 
व्याप्तिं गृट्णाति । तदनन्तरं कदाचित् पर्वतसमीपं गच्छति । तत्र पर्वते धूमं पश्यतः पुरुषस्य 'पर्वतो धूमवान्' इति पक्षधर्मताज्ञानमुत्पद्यते। तदनन्तरं पूर्वोत्पन्नव्याप्तनुभवजन्यसंस्कारोद्वोधात् व्याप्ते: स्मरणं भवति। एतादृशपक्षधर्मताज्ञानव्याप्तिस्मरणाभ्यां हि 'वहिन्याप्यधूमवान् अयं पर्वतः' इति परामर्शो जायते। ततः 'पर्वतो वहिनमान्' इत्यनुमितिः । इत्येवं व्याप्तिस्मृतिपरामर्शानुमितीनां किलोत्पत्तिक्रमः । अनुमितिः प्रमात्मिका । एतादृशानुमितेः करणमनुमानं भवति। परामर्शो व्यापारः। परामर्शः खलु कथं व्यापार ? इत्यत्रोच्यते - व्याप्तिस्मरणानन्तरं परामर्शोत्पत्तिः। तदनन्तरमनुमितिः। तथा च व्याप्तिस्मरणजन्यत्वे सति व्याप्तिस्मरणजन्यानुमितिजनकत्वरूपव्यापारत्वं परामर्शे वर्तत इति तस्य व्यापारत्वं सिद्धयति ।

प्राच्यास्तावदनुमितौ परामर्शो व्यापारो भवति। व्याप्तिज्ञानं करणं भवति। अनुमितौ व्याप्यलिंगविषयकज्ञानं करणम्। व्याप्यत्वेन ज्ञायमान लिड्गमनुमितौ करणमिति स्वीकुर्वन्ति। तन्न युक्तमिति नव्या:। तथा सति अनागतेन, विनष्टेन च लिड्गेनानुमितिर्न स्यात् । यथोक्त विश्वनाथेन कारिकायाम् -

अनुमायां ज्ञायमानं लिड्गं तु करणं न हि ।

अनागतादिलिड्गेन न स्यादनुमितिस्तदा ॥ (भट्टाचार्यः, सन् २००३, कारिका-६७)

इदमत्र बोध्यम्- 'इयं यज्ञशाला अतीतवहिनमती अतीतधूमात्', 'अयं महानस: भविष्यद्वहिनमान् भविष्यद्धूमात्' इत्यत्राप्यनुमिते: दर्शनात् । ज्ञायमानन्नाम वर्तमानकालीनज्ञानविषयीभूतम् । एतादृशस्थले तादृशं वर्तमानं लिड्गं न विद्यत इति कारणाभावेडपि कार्यभावाद् व्यतिरेकव्यभिचारः। व्याप्यत्वेन ज्ञायमानस्य लिड्गस्य (धूमस्य) तदानीमभावादनुमितेरभावः। दृश्यते चैतादृशस्थलेऽ नुमितिः । अतः ज्ञायमानं लिड्गन्न करणमपितु लिड्गज्ञान करणमिति बोध्यम्। लिड्गज्ञानस्य करणत्वे त्वनागतादिलिड्गकानुमितिरुत्पद्यते । लिड्गाभावेडपि लिड्गाविषयकस्मरणसत्वादिति । वैशेषिके लिड्गस्यैवानुमितिकरणत्वं स्वीक्रियते। तद्यथा वैशेषिकसूत्रोपस्कारे-

अनुमेयेन सम्बद्धं प्रसिद्धन्च तदन्विते

तदभावे तु नास्त्येव तल्लिड्गमनुमापकम् ॥

एतेन लिड्गमेवानुमितिकरणं न तु तस्य परामर्श:, तस्य निर्व्यापारत्वेनाकरणत्वात् । लिड्ग्गस्य तु स एव व्यापारः (मिश्रः, सन् १९६९, ४६७) इति ।

अनुमितिरपि द्वेधा विभज्यते। स्वार्थपरार्थानुमितिभेदादिति। येन स्वार्थानुमानेन स्वप्रयोजनसिद्धिः भवति, सा स्वार्थानुमितिः। येन परार्थानुमानेन परप्रयोजनसिद्धि: भवति, सा परार्थानुमितिः । न्याय इव वैशेषिके प्यनुमानस्य द्वैविध्यं स्वीक्रियते। यथोक्त शड्करमिश्रेण वैशेषिकसूत्रोपस्कारे तच्चानुमानं द्विविधम्"स्वार्थं परार्थन्च । तत्र स्वार्थं स्वयमेव व्याप्तिपक्षधर्मतयोरनुसन्धानात् । परार्थन्च परोदीरितन्यायजन्यव्याप्तिपक्षधर्मता ज्ञानम्” (मिश्र:, सन् १९६९, ४९३) इति। एतेनानुमानस्य द्वैविध्यादनुमितेरपि स्वार्थानुमितिपरार्थानुमितिभेदेन द्वैविध्यं नितरामेव सिद्धचति। एवंरीत्या न्यायवैशेषिकदर्शनाभिमतानुमितिप्रमा विवेचितेति दिक्। 


\section{६.१.३ उपमिति:}

इदानीमनुमितिज्ञानस्य निरूपणानन्तरमुपमितिज्ञानं निरूप्यते । उपमितिस्तु संज्ञासंज्ञिसम्बन्धज्ञानरूपा। संज्ञा नाम वाचक: शब्दः। संज्ञी वाच्यार्थः। तयो: "संज्ञासंज्ञानो: सम्बन्वो वाच्यवाचकभावरूपः। तस्य ज्ञानम् । तथा च पदवाच्यत्वप्रकारकज्ञानविशेषः उपमितिशब्दवाच्य इति भावः । एतेन पदपदार्थसम्बन्धविषयकत्वे सति ज्ञानत्वमुपमितेः लक्षणमिति स्पष्टीभवति। अयं गवयपदवाच्य इत्युपमितौ पदपदार्थसम्बन्धरूपवाच्यत्वविषयकत्वस्य ज्ञानत्वस्य च सत्वाल्लक्षणसमन्वयः। संज्ञा नाम पदम, संज्ञी नाम तस्य पदस्यार्थः, तयो: पदपदार्थयो: सम्बन्वो नाम शक्तिरिति। एवन्च पदपदार्थयोः सम्बन्धज्ञानमेवोपमितिरित्यर्थो लभ्यते। तदुक्तन्च संज्ञासंज्ञिसम्बन्धज्ञानमुपमितिः। तत्करणं सादृश्यज्ञानम्। अतिदेशवाक्यार्थस्मरणं व्यापारः" (भट्ट:, सन् २०१७, २३३) इति । गवयादिपदानां गोसादृश्यारण्यकपशौ 'गवयो गवयपदवाच्य:' इति ज्ञानमुपमिति: सैव फलमुच्यते। गोसदृशो गवयपदवाच्य इत्यतिदेशवाक्यार्थस्मरणं व्यापारो भवति । गोसदृशो गवयपदवाच्य इत्यतिदेशवाक्यार्थज्ञानमुपमानमिति । विश्वनाथस्त्वेवमाह -

ग्रामीणस्य प्रथमतः पश्यतो गवयादिकम् ।

सादृश्यधीर्गवादीनां या स्यात् सा करणं मतम् ॥

वाक्यार्थस्यातिदेशस्य स्मृतिर्व्यापार उच्यते ।

गवयादिपदानान्तु शक्तिधीरूपमा फलम् ॥ (भट्टाचार्य:, सन् २००३, कारिका ७९-५०)

प्रथमतो गवयादिक पश्यतः खलु ग्रामीणस्य पुरुषस्य गवादीनां या सादृश्यधी: 'अयं गोसदृशः' इत्याकारक गवयादिविशेष्यक गोसादृश्यप्रकारकप्रत्यक्षं स्यात्, तादृशधीरूपमितिकरणं भवतीत्यर्थः । यथा गवयपदार्थमजानन् कश्चिज्जन: आरण्यकपुरुषात् 'गोसदृशो गवय:' इति श्रुत्वा कदाचित् अरण्यं गच्छाति। तत्र गोसदृशमेव पिण्डं दृष्ट्वाप्तोक्तवाक्यं स्मरति, ततः 'अयं गवयपदवाच्य:' इत्याकारकमुपमितिज्ञानं तस्य पुरुषस्य जायते। तादृशं ज्ञानमतिदेशवाक्यार्थज्ञानात्मकेनोपमानप्रमाणेनोत्पद्यते । उपमानन्नाम उपमितिनिरूपितकरणत्वम्। तथा च उपमितित्वावच्छिन्नकार्यतानिरूपितकारणताश्रयत्वे सति, उपमितिजनकव्यापारजनकत्वमित्यर्थः।

उपमितित्वावच्छिन्ना कार्यता हि 'गवयो गवयपदवाच्य:' इत्याकारकगवयत्वावच्छिन्नविशेष्यक गवयपदवाच्यत्वप्रकारकोपमितौ विद्यमाना, तादृशकार्यतानिरूपितकारणता च 'गोसदृशो गवयपदवाच्य:' इत्याकारकगोसदृशत्वावच्छित्नविशेष्यक-गवयपदवाच्यत्वप्रकारकज्ञानात्मकोपमाननिष्ठा, तदाश्रयत्वस्य 'गोसदृशो गवयपदवाच्य:' इत्याकारकातिदेशवाक्यार्थविषयकस्मरणरूपव्यापारजनकत्वस्य च 'गोसदृशो गवयपदवाच्य:' इत्याकारकातिदेशवाक्यार्थज्ञानरूपोपमाने विद्यमानत्वाल्लक्षणसमन्वयः ।

\section{वैशेषिकरीत्योपमिते: पृथक्प्रमात्वाभावोपपादनम्-}

वैशेषिकै: उपमानप्रमाणस्य पृथक्तया प्रमाणत्वास्वीकृतत्वादेवोपमितिप्रमाया अपि विवेचनावसरो न दृश्यते । एतन्मते उपमानप्रमाणस्य शब्देडन्तर्भाव इति । शब्दस्तु पुनः अनुमानमेव । तदुक्त ्च 
प्रशस्तपादभाष्ये यत् “आप्तेनाप्रसिद्धस्य गवयस्य गवा गवयप्रतिपादनादुपमानमाप्तवचनमेव" (देवाचार्यः, सन् २०१६, १७६) इति। तथा हि 'गोसदृशो गवय:' इत्यत्र शब्दश्रवणस्यावश्यकत्वादर्थाद् गोसादृश्येन गवा गवयस्य निरूपितत्वाद् यथा गौस्तथा गवय इत्याकारकातिदेशवाक्यस्यापि आप्तत्वादेवोपमानस्य शब्दे डन्तर्भावः। शब्दप्रमाणन्तावदनुमानमेवेति प्रतिपादनादुपमानमपि अनुमानान्तर्गतमेवेति सिद्धयति। एवमेव वैशेषिकसूत्रोपस्कारे प्युक्तं विद्यते यत् “तत्रोपमानं तावदनुमानमेव शब्दद्वारा। ..... यद्वा गवयशब्दो गवयवाचक:, असति वृत्त्यन्तरे शिष्टैस्तत्र प्रयुज्यमानत्वात्, असति वृत्त्यन्तरे यः शब्दो यत्र शिष्टैः प्रयुज्यते, स तस्य वाचको यथा सहकारी वाच्यः। स वरमनुमाने क्लृप्तप्रमाणभावेडस्तु किं कल्पनीयप्रमाणभावेनोपमानेनेति" (मिश्र:, सन् १९६९, ४०७-४०६)। एतेनोपमानस्य पृथक्प्रमाणाभावादुपमितेरपि पृथक्तया प्रमात्वाभावः सिद्धचति । तथा चोपमितिज्ञानस्यानुमितिज्ञाने डन्तर्भाव इत्यवगम्यते । एवंरीत्या न्यायवैशेषिकदर्शनाभिमतोपमितिप्रमा विवेचितेति दिक् ।

\section{६.१.४ शाब्द:}

उपमितिज्ञानस्य निरूपणानन्तरमिदानीं शाब्दप्रमा निरूप्यते । प्रमास्वन्तिमप्रमेयं शाब्दप्रमा । शब्दाज्जायमानं ज्ञानं शाब्दमिति, अर्थात् शब्दप्रमाणेनोत्पन्नं ज्ञानं शाब्दो भवतीति। यद्वा यथार्थवक्रा प्रयुक्तशब्दानां श्रवणानन्तरं जायमानं ज्ञान शाब्दप्रमेति निष्कर्षः। शब्दो नाम क: ? इति प्रश्ने, उच्यते न्यायसूत्रे-“आप्तोपदेश: शब्द:" (न्यायसूत्रम, १।१।७) इति। एतेनाप्तप्रयुक्तत्वे सति वाक्यत्वं शब्दप्रमाणस्य लक्षणं स्पष्टीभवति। वाक्यत्वं शब्दप्रमाणस्य लक्षणमित्येतावन्मात्रोक्तौ अनाप्तोच्चरितवाक्येडिव्याप्तिः । अतस्तद्वारणाय आप्तप्रयुक्तत्वे सतीति विशेषणपद निवेश्यम् । आप्तप्रयुक्तत्वं शब्दप्रमाणस्य लक्षणमित्येवोच्यते चेत्तर्हि ‘अइडण्' इत्यादावतिव्याप्तिः । तन्निवारणाय वाक्यत्वमिति विशेष्यपदमपि निवेशनीयम् । 'अइउण्' इत्यादीनामाप्तप्रयुक्तत्वेडपि वाक्यत्वाभावान्नातिव्याप्तिः ।

अत्रेदं चिन्तनीयम्- आप्तोक्तवाक्यस्यैव प्रमाणत्वं न त्वनाप्तोक्तवाक्यस्येति । आप्तस्तावद् यथार्थवक्तैव । तदुपदेश एव शब्दः । वाक्यं पुनः पदसमूहात्मकम्। यथा 'गामानय' इत्यादि। शाब्दप्रमायां पदविषयक ज्ञानं करणम, पदजन्यपदार्थस्मरणं व्यापार:, शाब्दबोधः (वाक्यार्थबोधः) फलम, शक्तिज्ञानज्च सहकारिकारणं भवतीति ज्ञेयम् । तदुक्तम्-

"पदज्ञानं तु करणं द्वारं तत्र पदार्थधीः। शाब्दबोध: फलं तत्र शक्तिधी: सहकारिणी ॥" (भट्टाचार्यः, सन् २००३, कारिका-६१) पदसमूहात्मकवाक्यजन्यो यो वाक्यार्थबोधः, सा प्रमोच्यते। शब्दस्य दृष्टादृष्टभेदेन द्वैविध्यमित्यपि बोध्यम् ।

\section{वैशेषिकरीत्या शाब्दस्य पृथक्प्रमात्वाभावोपपादनम्-}

वैशेषिकै: शब्दप्रमाणस्य पृथक्तया प्रमाणत्वं न स्वीक्रियते तः शाब्दप्रमाया अपि नास्ति प्रतिपादनावसरः। एतन्मते शब्दप्रमाणस्यानुमाने ऽन्तर्भावादेव शाब्द ज्ञानस्याप्यनुमितिज्ञाने $ड$ न्तर्भाव इति ज्ञेयम्। शब्दोऽनुमानमेव (शाब्दबोधोडनुमितिरेवेति वा) वदन् कणाद: सूत्रं प्रस्तौति यत्- "एतेन शाब्दं व्याख्यातम्" 
(वैशेषिकसूत्रम्, ९-२-३) इति । अस्यार्थ:- एतेन=अनुमानप्रमाणेन, शाब्दम्=शब्दाज्जायमानं ज्ञानमुत शब्दकरणकं ज्ञानम, व्याख्यातमिति। किन्च 'घटं पश्यामि' इत्यादिवाक्यघटकशब्दा:, परस्परान्वितार्थबोधका:, साकाड्क्षशब्दत्वात्, गामानयेति वाक्यघटकशब्दवदित्यनुमानेन शब्दोड नुमानमेवेति सिद्धयति। शड्करमिश्रोडपि एताद्शमेव भावं प्रकटयति यत् "एते पदार्था: मिथः संसर्गवन्तः आकाड़क्षादिमद्भिः स्मारितत्वात् गामभ्याजेति पदार्थसार्थवत्" (मिश्र:, सन् १९६९, ४९६) इत्यनुमानेन शब्दस्यानुमाने ऽन्तर्भाव इति तु स्पष्टमेव ।

प्रशस्तपादभाष्ये "शब्दादीनामप्यनुमाने डन्तर्भाव: समानविधित्वात् । यथा प्रसिद्धसमयस्यासन्दिग्धलिड्गदर्शनप्रसिद्धचनुस्मरणाभ्यामतीन्द्रिये र्थे भवत्यनुमानमेवं शब्दादिभ्योऽपीति" (देवाचार्यः, सन् २०१६, १७३) एवंरीत्या शब्दस्यानुमानत्वं प्रतिपादयति ग्रन्थकारः । अस्यार्थस्तु यथा व्याप्तिज्ञानवतः पुरुषस्यासन्दिगधहेतुदर्शनव्याप्तिस्मरणाभ्यामप्रत्यक्षेर्थे भवत्यनुमानम्, तद्वृ शब्दादिनाप्यनुमानं सम्भवतीति। एतेन शब्दस्य पृथक्प्रमाणत्वाभावात् शाब्दप्रमाया अपि पृथक्तया प्रमात्वाभावः सिद्धयति। तथा च शाब्दज्ञानस्यानुमितिज्ञाने डन्तर्भाव इत्यवगम्यते। अत्र हि शब्दप्रमाणस्य द्वैविध्यात् शाब्दप्रमाया अपि द्वैविध्यमित्यपि न विस्मर्तव्यम् । एवंरीत्या न्यायवैशेषिकदर्शनाभिमतशाब्दप्रमा विवेचितेति दिक् ।

\section{७. निष्कर्ष:}

पौरस्त्यदर्शनचिन्तनजगति बहुविधानि दर्शनानि विद्यन्ते। तन्मध्ये गौतमीयं न्यायदर्शनं प्रमाणविचारप्रधानमिति तु जानन्ति तत्त्वविदः । जगति विद्यमानानां पदार्थानां खलु सिद्धि: प्रमाणेनैव भवति। प्रमाणजन्यं ज्ञानं प्रमेति। तत्र ज्ञानं द्विविधं स्मृत्यनुभवभेदेन। अनुभवोऽपि यर्थार्थायथार्थभेदेन द्विविधः । प्रमा तावत् तद्वति तत्प्रकारकानुभव:, अर्थात् रजतं दृष्ट्वा इदं रजतमिति ज्ञाने रजतत्वप्रकारकरजतविशेष्यकत्वस्य विद्यमानत्वादिदं ज्ञानं प्रमेति निष्कर्ष: प्रदत्तो वर्तते त्रालेखे । एवज्च तद्वन्निष्ठविशेष्यतानिरूपकत्वे सति तन्निष्ठप्रकारतानिरूपकत्वे सत्यनुभवत्वं यथार्थानुभवस्य लक्षणमिति निकृष्टलक्षणत्वेन निष्कर्ष: प्रस्तुतो विद्यते। किज्च प्रमाभेदनिरूपणायाप्ययं प्रयासो विहितः । आलेखेऽस्मिन् पुस्तकालयीयविधिमवलम्ब्य अनुसन्धानं कृतं वर्तते। तत्रापि विशेषतः संस्कृतमूलाकरग्रन्था: प्रमुखसामग्रीत्वेन प्रयुक्ता वर्तन्ते । प्रथम प्रमाभेद प्रदर्श्य प्रत्यक्षानुमित्युपमितिशाब्दानां ऋमशो विवेचनं कृतमस्ति। वैशेषिकदर्शनदृष्टया प्रत्यक्षमनुमितिश्चेति प्रमादूयं विश्लेषितम् । प्रमाया: लक्षणप्रतिपादनावसरे प्रत्यक्षादिचतुर्विधप्रमाणां विश्लेषणावसरे च गौतमादारभ्य वात्स्यायन-उद्योतकर-वाचस्पति-उदयन-केशवमिश्र-विश्वनाथ-अन्नम्भट्टादिन्यायाचार्याणां कणादादारभ्य प्रशस्तपाद-शड्करमिश्रयोश्च मतं प्रदर्श्य तद्गतं वस्तुतत्त्वं प्रकटीकृतं वर्तते ।

न्यायदर्शने वैशेषिकदर्शने च प्रतिपादितस्य प्रमास्वरूपस्याध्ययनेन प्रमाविषये कुत्रचित् साम्यं कुत्रचिच्च वैषम्यं दरीदृश्यते। तत्र प्रमायास्स्वरूपपतिपादने तु साम्यमेव दृश्यते। यतो हि उपलब्धिरेव प्रमा, उत यथार्थानुभव: प्रमा इत्यत्र उभयो: तात्त्विकभेदो न दृश्यते। प्रमाया: संख्याविषये तु वैषम्यं स्पष्टमेव दृश्यते। तत्र नैयायिकै: प्रत्यक्षानुमित्युपमितिशाब्दभेदेन प्रमायाशचातुर्विध्यं स्वीक्रियते चेद् वैशेषिकै: प्रत्यक्षानुमितिभेदेन द्वैविध्यमेव स्वीक्रियत इति प्रमायास्संख्याविषये तयो: वैषम्यम्। प्रमाया लक्षणमनेकैराचार्यै: भिन्नभिन्नरूपेण 
कृतन्तथापि सर्वेषामाचार्याणामाशयं गृहीत्वा तदून्निष्ठविशेष्यतानिरूपकत्वे सति तन्निष्ठप्रकारतानिरूपकत्वे सत्यनुभवत्वं प्रमात्वमिति निष्कर्षो दत्तो वर्तते ।

\section{कृतज्ञताज्ञापनम्}

आलेखेडस्मिन् न्यायवैशेषिकदर्शनदृष्टया प्रमास्वरूपविश्लेषणक्रमे सैद्धान्तिकविषयवस्तुनिरूपणे अथ चानुसन्धानात्मकालेखगतप्रविध्यादिविषयेडपि परामर्शदातृभ्यो विद्द्भ्यो धन्यवादं ज्ञापयन् सूक्ष्मेक्षिकया चालेखमिदमाद्यन्तमालोडच सम्परीक्ष्य च यथावश्यकं खलु परामर्शदातृभ्यो विषयविज्ञेभ्यो गुरुभ्योऽपि हार्दिकीं कृतज्ञतां व्यनज्मि ।

\section{सन्दर्भग्रन्थसूची}

आचार्य:, कणाद: (सन् १९५७), वैशेषिकदर्शनम, (व्याख्याता. नारायणमिश्र:), वाराणसी : चौखस्भासंस्कृतसंस्थानम्। आचार्य:, उदयन: (सन् १९६६). न्यायकुसुमाज्जलिः; (हरिदासीटीकासहितः) वाराणसी : चौखम्बाविद्याभवनम्। आचार्य:, गौतमः (सन् १९७६). न्यायदर्शनम, "वात्स्यायनभाष्यसहितम्" (सम्पादकः द्वारिकादासशास्त्री), वाराणसी : बौद्धभारतीप्रकाशनम् ।

उद्योतकर:, भारद्वाजः (सन् २००७). न्यायवार्तिकम, (पुनर्मुद्रणम्), वाराणसी : चौखम्बासंस्कृतभवनम् । देवाचार्यः, प्रशस्तः (सन् २०१६). प्रशस्तपादभाष्यम, (व्याख्याता. ढुण्ढिराजशास्त्री), वाराणसी : चौखम्भासंस्कृतसंस्थानम्। भट्टः, अन्नम् (सन् २००६). तर्कसंग्रहः, "आलोकव्याख्यासहित:" (व्याख्याता. के. एस्. वरदाचार्य:) महीशूरपुरी, कर्णाटक: : आर्षग्रन्थप्रकाशनम् ।

भट्टः, अन्नम् (सन् २०१७). तर्कसंग्रहः; "दीपिकान्यायबोधिनिपदकृत्यश्रीधरमुखोल्लासिनिव्याख्यासहित:"

(सम्पादक: गोविन्दाचार्य:), वाराणसी : चौखम्बासुरभारतीप्रकाशनम् ।

भट्ट:, जयन्तः (सन् १९६४). न्यायमज्जरी, वाराणसी : सम्पूर्णानन्दसंस्कृतविश्वविद्यालयः ।

भट्टाचार्य:, विश्वनाथपज्चाननः (सन् २००३). न्यायसिद्धान्तमुक्तावली, (किरणावलीसमाख्यव्याख्योपेता),

(व्याख्याता. पं. कृष्णवल्लभाचार्य:), (षण्ठसंस्करणम्), वाराणसी : चौखम्बासंस्कृतसंस्थानम्।

मिश्र:, केशव: (सन् २००३). तर्कभाषा, 'आशुबोधिनिहिन्दीव्याख्योपेता' (व्याख्याता. सुरेन्द्रदेवशास्त्री), वाराणसी : चौखम्बाविद्याभवनम् ।

मिश्र:, जगदीशचन्द्र: (सन् २०१९). भारतीय दर्शन, वाराणसी : चौखम्बासुरभारतीप्रकाशनम् ।

मिश्र:, वाचस्पतिः (सन् २०१३). न्यायवार्तिकतात्पर्यटीका, (तृतीयसंस्करणम्), वाराणसी : चौखम्बासंस्कृतभवनम् ।

मिश्र:, शंकरः (सन् १९६९). वैशेषिकसूत्रोपस्कार:, (व्याख्याता. ढुण्ढिराजशास्त्री) वाराणसी : चौखम्भासंस्कृतसंस्थानम् ।

शर्मा, राममूर्तिः (सन् १९९६). न्यायवैशेषिक एक चिन्तन, दिल्ली : राष्ट्रियसंस्कृतसंस्थानम्। शास्त्री, द्वारिकादास: (सम्पादक:). (सन् १९९६), षड्दर्शनसूत्रसड्ग्रहः; वाराणसी : बौद्वभारती। 